\title{
Dichotomous Thinking Leads to Entity Theories of Human Ability ${ }^{*}$
}

\author{
Atsushi Oshio \\ Waseda University, Tokyo, Japan
}

\begin{abstract}
Previous research has indicated that dichotomous thinkers have stereotypic and rigid views of others. This study focuses on the world-view of dichotomous thinkers from the perspective of entity vs. incremental theory. Study 1 explored the relationship between dichotomous thinking and the IPTM (implicit person theory measure) (Dweck, Chiu, \& Hong, 1995). Two hundred and forty-eight Japanese undergraduates completed the DTI (dichotomous thinking inventory) and the IPTM. A significant positive relationship between the variables was found. Study 2 explored the relationship between the DTI and another measure assessing the degree to which participants endorsed implicit theories. Three hundred and eleven Japanese undergraduates completed the DTI and the SITI (scale of implicit theory of intelligence) (Mori, Ishida, Shimizu, \& Tominaga, 2001). Factor analysis of the SITI revealed four factors: smartness, efficiency, clear-headedness, and grade and knowledge. Correlation analyses indicated that people who think dichotomously tend to deem human abilities to be more innate.
\end{abstract}

Keywords: dichotomous thinking, implicit theory of intelligence, stereotype, human ability

\section{Introduction}

We find it hard to apply the knowledge of ourselves to our judgment of others. The fact that we are never of one kind that we never love without reservations and never hate with all our being cannot prevent us from seeing others as wholly black or white.

Eric Hoffer

Dichotomous thinking is the propensity to think of things in terms of binary opposition, such as "black or white", "good or bad", or "all or nothing”. This thinking style can be viewed as the tendency to get stuck in either the thesis or the antithesis, unable to move toward synthesis (Linehan, 1993). In other words, dichotomous thinking is an "either-or" kind of thinking and not an "and" kind of thinking (Neuringer, 1961).

Dichotomous information and judgments can be observed in daily life. In political settings, some people enthusiastically support politicians who give simple and dichotomous messages. Defendants plead either guilty or not guilty to the charges against them in the criminal court system. A great deal of simplified, such as "us-or-them”, "good-or-bad" and "useful-or-not” information is reported by the mass media everyday (Mori, 2006), and some people prefer this kind of news.

\footnotetext{
* This research uses reanalyzed data from a poster presented at the ISSID 2011 (International Society for the Study of Individual Differences), London UK, at the joint Conference of the 19th JSRE (Japan Society for Research on Emotions), and at the 20th JSPP (Japan Society of Personality Psychology), Kyoto, Japan.

Atsushi Oshio, Ph.D., associate professor, Faculty of Letters, Arts and Sciences, Waseda University.
} 
Some people prefer thinking dichotomously, but others do not. Individual differences can be observed in this thinking style. Byrne, Cooper, and Fairburn (2004) developed the "dichotomous thinking in eating disorder scale" to assess individual difference in dichotomous thinking, especially in attitudes towards food and food intake. The DTI (dichotomous thinking inventory) was developed for general use in psychological studies rather than specifically for eating problems (Oshio, 2009a). The DTI has good internal consistency and test-retest reliability, and good validity as determined by correlations with other self-measures and characteristics reported by respondents’ friends. Recently, Oshio (2012) reported that individuals who score high on the DTI prefer rock, alternative, soul, funk and heavy-metal music, and dislike classical music. This study suggests that this thinking style could influence daily activities.

Dichotomous thinking is also linked to negative psychological outcomes in specific contexts. For example, eating disorders (Byrne, Allen, Dove, Watt, \& Nathan, 2008; Byrne, Cooper, \& Fairburn, 2004), suicide attempts (Neuringer, 1961), and personality disorders (Oshio, in press) are related with such thinking styles. Oshio (2009b) examined the relationship between individual differences in thinking dichotomously and participants' evaluation of their degree of attraction to women and reported that this thinking style lowered participants' evaluations of less-attractive women. The results indicated that people who think dichotomously tend to undervalue an individual when they perceive his/her negative aspects.

An individual's implicit theory of intelligence is known to affect his/her goals, efforts, and achievements. People who believe that others' traits are fixed are called "entity theorists", whereas "incremental theorists" are those who believe that others' traits are malleable (Dweck \& Leggett, 1988). It has also been shown that implicit theories predict differences in the degree of social stereotyping (Levy, Stroessner, \& Dweck, 1998). Recently, Shih (2011) reported that maladaptive perfectionism, which is associated with being overly concerned with how others evaluate oneself and worrying over making mistakes, is positively related with holding an entity theory of intelligence among Taiwanese students. This indicates that a rigid thinking style may relate to the entity theory of intelligence. However, no previous studies have explored relationships between dichotomous thinking and implicit theories. If dichotomous thinking leads to an inflexible view of others (Oshio, 2009b), it is hypothesized that this thinking style and the entity theory of human abilities are positively related to each other.

In this paper, two studies are described in which the relationship between dichotomous thinking and implicit theories is explored to clarify the link between dichotomous thinking and the tendency to judge others stereotypically.

\section{Study 1}

In Study 1, relationships between dichotomous thinking and the degree to which participants endorsed entity theories as assessed using the IPTM (implicit person theory measure) (Dweck, Chiu, \& Hong, 1995) are explored.

\section{Method}

Participants. A total of 248 Japanese undergraduates (82 males and 166 females) participated in Study 1. Their average age was 20.0 years $(S D=1.7)$.

\section{Materials}

Dichotomous thinking. The DTI (Oshio, 2009a) was used to assess the degree of each individual dichotomous thinking. The DTI consists of three subscales: The "preference for dichotomy" subscale indicates 
a thinking style that is drawn towards distinctness and clarity rather than ambiguity and obscuration; The "dichotomous belief" subscale indicates a manner of thinking that considers all things in the world as being capable of division into two types, such as inseparable and indivisible; The "profit-and-loss thinking" subscale indicates motivation by an urge to gain access to actual benefits and to avoid disadvantages. The DTI was administered using a 6-point scale ( $1=$ "Strongly disagree"; 6 = "Strongly agree"). Cronbach's alpha ranged from 0.68 (profit-and-loss) to 0.82 (total of the DTI) in Study 1.

IPTM. In order to measure entity versus incremental theory of the person as a whole, the IPTM (Dweck et al., 1995) was used. The measure consists of three items: "The kind of person someone is, is something basic about them, and it cannot be changed very much"; "People can do things differently, but the important parts of whom are cannot really be changed"; "Everyone is a certain kind of person, and there is not much that they can do really change that". The three items were translated into Japanese in this study. Respondents indicated their agreement with these statements on a 6-point scale from $1=$ "Strongly disagree" to 6 = "Strongly agree”. Higher scores indicate stronger entity theory. Cronbach's alpha was 0.74 in this study.

\section{Results}

Table 1 shows the correlation coefficients between dichotomous thinking and the IPTM. The total score of the DTI had a significant positive correlation with the IPTM $(r=0.29, p<0.001)$. Preference for dichotomy and dichotomous belief had a low but significant positive relationship with the IPTM $(r=0.19, p=0.003 ; r=$ $0.15, p=0.02$, respectively). Profit-and-loss thinking and the IPTM are moderately related to each other ( $r=$ $0.34, p<0.001)$.

Table 1

Correlations Between DTI and IPTM

\begin{tabular}{lllll}
\hline & & & DTI & \\
\cline { 2 - 4 } & Total & Preference for dichotomy & Dichotomous belief & Profit-and-loss thinking \\
\hline IPTM & $0.29^{* * *}$ & $0.19^{* *}$ & $0.15^{*}$ & $0.34^{* * *}$ \\
\hline
\end{tabular}

Notes. ${ }^{*} p<0.05,{ }^{* *} p<0.01,{ }^{* * *} p<0.001$.

Table 2 shows a hierarchical multiple regression analysis of the IPTM as a dependent variable. After controlling for participants' age and sex, only profit-and-loss thinking had an effect on the IPTM.

Table 2

Effects of Dichotomous Thinking on IPTM

\begin{tabular}{lll}
\hline & & IPTM \\
\hline \multirow{3}{*}{ Step 1} & Age & 0.04 \\
& Sex & 0.04 \\
& $R^{2}$ & 0.01 \\
\hline \multirow{4}{*}{ Step 2} & Preference for dichotomy & -0.03 \\
& Dichotomous belief & 0.06 \\
& Profit-and-loss thinking & $0.33^{* * *}$ \\
& Delta $R^{2}$ & $0.11^{* * *}$ \\
& $R^{2}$ & $0.12^{* * *}$ \\
\hline
\end{tabular}

Note. ${ }^{* * *} p<0.001$. 


\section{Study 2}

Study 2 focuses on some domain-specific factors of implicit theories and explores their relationships with dichotomous thinking.

\section{Method}

Participants. The participants were 311 Japanese undergraduates (130 males and 181 females). Their average age was 19.4 years $(S D=1.3)$.

\section{Materials}

Dichotomous thinking. The DTI (Oshio, 2009a) was used as in Study 1. Cronbach's alpha ranged from 0.74 (preference) to 0.87 (total of the DTI).

Implicit theories. In order to assess participants' implicit theories of intelligence, the SITI (scale of implicit theory of intelligence) (Mori, Ishida, Shimizu, \& Tominaga, 2001) was used. The SITI consists of 20 items regarding human's ability, for example, "having a good memory", "working efficiently", and "being decisive”. The SITI was administered using a 6-point scale ( 1 = "Not inborn ability at all”; 6 = "Entirely inborn ability”), and a high score indicated that the participant ias an entity theorist.

Table 3

Factor Structure of the Scale of Implicit Theory of Intelligence

\begin{tabular}{|c|c|c|c|c|c|c|}
\hline & & & I & II & III & IV \\
\hline \multirow{6}{*}{ Smartness } & 18. & Being decisive & 0.87 & -0.07 & 0.10 & -0.14 \\
\hline & 16. & Having a quick wit & 0.72 & -0.02 & 0.10 & 0.00 \\
\hline & 19. & Not wasting time & 0.69 & -0.02 & -0.15 & 0.12 \\
\hline & 17. & Looking at things from various angles & 0.66 & 0.04 & -0.01 & 0.04 \\
\hline & 20. & Having good insight & 0.59 & -0.02 & 0.29 & -0.08 \\
\hline & 14. & Being a good listener & 0.47 & 0.25 & -0.14 & 0.10 \\
\hline \multirow{5}{*}{ Efficiency } & 5. & Working efficiently & -0.11 & 0.83 & 0.12 & -0.01 \\
\hline & 6. & Talking systematically & 0.08 & 0.82 & 0.02 & -0.05 \\
\hline & 7. & Leading different opinions to consensus & 0.15 & 0.66 & 0.03 & 0.01 \\
\hline & 4. & Being conversational & 0.19 & 0.52 & 0.06 & -0.02 \\
\hline & 1. & Being a good writer & -0.10 & 0.45 & -0.06 & 0.14 \\
\hline \multirow{5}{*}{ Clear-headedness } & 8. & Having a good memory & -0.13 & -0.01 & 0.82 & -0.09 \\
\hline & 13. & Having a sharp mind & 0.21 & 0.04 & 0.59 & -0.04 \\
\hline & 9. & Making a quick judgment & 0.12 & 0.14 & 0.59 & 0.05 \\
\hline & 12. & Grasping the gist of a discussion & -0.05 & 0.22 & 0.52 & 0.23 \\
\hline & 15. & Being good with numbers & 0.14 & -0.24 & 0.37 & 0.36 \\
\hline \multirow{4}{*}{$\begin{array}{l}\text { Grade and } \\
\text { knowledge }\end{array}$} & 11. & Having a good record at school & -0.14 & -0.10 & 0.25 & 0.65 \\
\hline & 3. & Having a good vocabulary & -0.04 & 0.24 & -0.19 & 0.50 \\
\hline & 10. & Having something interesting to talk about & 0.27 & 0.10 & -0.22 & 0.49 \\
\hline & 2. & Studying hard & 0.04 & 0.10 & 0.07 & 0.37 \\
\hline \multirow{4}{*}{$\begin{array}{l}\text { Inter-factor } \\
\text { correlations }\end{array}$} & I & & - & 0.70 & 0.61 & 0.46 \\
\hline & II & & - & - & 0.50 & 0.48 \\
\hline & III & & - & - & - & 0.34 \\
\hline & IV & & - & - & - & - \\
\hline
\end{tabular}




\section{Results}

Factor analysis of the implicit theories. In order to explore the structure of the SITI, an exploratory maximum likelihood factor analysis with promaxrotation of the implicit theory was conducted for the 20 items (see Table 3). A four-factor solution seemed to be appropriate because four of the eigenvalues were more than 1.00: 7.72, 1.67, 1.40, and 1.16, in descending order. These four factors accounted for $49.7 \%$ of the total variance.

Factor 1 included six items, such as "being decisive”, "having a quick wit”, and "not wasting time”. These items conjure the image of person who is smart, astute, and shrewd, so this factor was named "smartness". Factor 2 consisted of five items, such as "working efficiently", "talking systematically", and "leading different opinions to consensus". The emphasis in these items was on the ability to perform any task successfully without wasting energy, so this factor was termed "efficiency". Factor 3 included "having a good memory", "having a sharp mind", "making a quick judgment" and "grasping the gist of a discussion". These items indicate a person's intelligence and having a good head on one's shoulders. This factor was termed "Clear-headedness". Factor 4 included "having a good record at school”, "having a good vocabulary" and "having something interesting to talk about", and was termed "grade and knowledge". Following the factor analysis, the scores of the four factors of the SITI were calculated.

Table 4

Correlations Between DTI and SITI

\begin{tabular}{lllll}
\hline \multirow{2}{*}{ SITI $^{1}$} & \multicolumn{3}{c}{ DTI } \\
\cline { 2 - 4 } & Total & Preference for dichotomy & Dichotomous belief & Profit-and-loss thinking \\
\hline Smartness & $0.23^{* * *}$ & $0.21^{* * *}$ & $0.24^{* * *}$ & $0.11^{*}$ \\
Efficiency & $0.15^{* *}$ & $0.14^{*}$ & $0.18^{* *}$ & 0.05 \\
Clear-headedness & $0.18^{* *}$ & $0.21^{* * *}$ & 0.06 & $0.17^{* *}$ \\
Grade and knowledge & 0.09 & 0.06 & $0.20^{* * *}$ & -0.03 \\
\hline
\end{tabular}

Notes. ${ }^{*} p<0.05,{ }^{* *} p<0.01,{ }^{* * *} p<0.001 ;{ }^{1}$ A high score indicates stronger entity theory.

Table 5

Regression Effects of the DTI on the SITI

\begin{tabular}{|c|c|c|c|c|c|}
\hline & & \multicolumn{4}{|c|}{ SITI $^{1}$} \\
\hline & & Smartness & Efficiency & Clear-headedness & Grade and knowledge \\
\hline & & \multicolumn{4}{|c|}{ beta } \\
\hline \multirow{3}{*}{ Step 1} & Age & -0.06 & -0.09 & -0.02 & -0.06 \\
\hline & Sex & 0.10 & 0.09 & 0.06 & $0.13^{*}$ \\
\hline & $R^{2}$ & 0.01 & $0.02^{*}$ & 0.01 & $0.02^{*}$ \\
\hline \multirow{5}{*}{ Step 2} & $\begin{array}{l}\text { Preference for } \\
\text { dichotomy }\end{array}$ & $0.20^{*}$ & $0.16^{*}$ & $0.19^{*}$ & 0.08 \\
\hline & $\begin{array}{l}\text { Dichotomous } \\
\text { belief }\end{array}$ & $0.17^{* *}$ & $0.14^{*}$ & -0.06 & $0.21^{* * *}$ \\
\hline & $\begin{array}{l}\text { Profit-and-loss } \\
\text { thinking }\end{array}$ & -0.11 & $-0.13^{*}$ & 0.06 & $-0.19^{* *}$ \\
\hline & Delta $R^{2}$ & $0.04^{*}$ & $0.04^{* *}$ & $0.04^{* *}$ & $0.06^{*}$ \\
\hline & $R^{2}$ & 0.07 & $0.06^{* *}$ & $0.05^{* *}$ & $0.07^{* * *}$ \\
\hline
\end{tabular}

Notes. ${ }^{*} p<0.05,{ }^{* *} p<0.01,{ }^{* * *} p<0.001 ;{ }^{1}$ A high score means thinking them as entity theory. 
Relationship between dichotomous thinking and implicit theories. Table 4 shows correlation coefficients between the DTI scores and the SITI. The DTI total score, preference for dichotomy and dichotomous belief had positive correlations with implicit theories, indicating that people who had this thinking style tended to be entity theorists.

Table 5 shows hierarchical multiple regression analyses of the implicit theory factors as dependent variables. After controlling for participants' age and sex, the preference for dichotomy had a significant positive effect on smartness, efficiency and clear-headedness. Dichotomous belief positively influenced smartness, efficiency, and grade and knowledge. On the other hand, profit-and-loss thinking had a significant negative effect on efficiency and grade and knowledge.

\section{Discussion and Conclusions}

As anticipated, correlation analyses indicated that people who think dichotomously tend to deem human abilities to be more innate. In Study 1, dichotomous thinking, especially the profit-and-loss thinking subscale, seems to lead to the entity theory of the person as a whole (Dweck et al., 1995). In Study 2, this thinking style was found to be related to the entity theory of specific human abilities. These results suggest that dichotomous thinking is linked to viewing others in unchangeable, fixed, and stereotypic ways.

In Study 2, the factor analysis of the SITI revealed a four-factor structure of the implicit theory of intelligence. Interestingly, profit-and-loss thinking works as a suppressor variable to negative effects on the entity theory of efficiency and grade and knowledge.

What is the reason for the incongruity in the effects of profit-and-loss thinking on implicit theories? Such thinking represents focusing on one's own benefits and advantages, and people with this thinking style may avoid disadvantages. The factors of efficiency and grade and knowledge both involve the ability to do any task successfully without wasting energy. These may link more directly to advantages in everyday life than do smartness and clear-headedness, especially among university students. For these reasons, students who highly value profit-and-loss may consider efficiency and grade and knowledge to be malleable and flexible.

From this perspective, it is necessary to assess the importance that people place on the four abilities of the SITI. Furthermore, future studies need to focus on the mediating effects of an implicit-theory thinking style and social stereotyping.

\section{References}

Byrne, S. M., Allen, K. L., Dove, E. R., Watt, F. J., \& Nathan, P. R. (2008). The reliability and validity of the dichotomous thinking in the eating disorders scale. Eating Behaviors, 9, 154-162.

Byrne, S. M., Cooper, Z., \& Fairburn, C. G. (2004). Psychological predictors of weight regain in obesity. Behavior Research and Therapy, 42, 1341-1356.

Dweck, C. S., Chiu, C. Y., \& Hong, Y. Y. (1995). Implicit theories and their role in judgments and reactions: A world from two perspectives. Psychological Inquiry, 6, 267-285.

Dweck, C. S., \& Leggett, E. L. (1988). A social-cognitive approach to motivation and personality. Psychological Review, 95, 256-273.

Levy, S. R., Stroessner, S. J., \& Dweck, C. S. (1998). Stereotype formation and endorsement: The role of implicit theories. Journal of Personality and Social Psychology, 74, 1421-1436.

Linehan, M. M. (1993). Cognitive-behavioral treatment of borderline personality disorder. New York: Guildford Press.

Mori, T. (2006). Before all people stop thinking completely. Tokyo: Kodansha. (in Japanese) 
Mori, T., Ishida, M., Shimizu, M., \& Tominaga, M. (2001). What factors do affect students' self-educational abilities? Effects of learning goals, causal attribution, self-efficacy, and the implicit theory of intelligence. Bulletin of the Graduate School of Education, Hiroshima University: Part 1, Learning and Curriculum Development, 50, 1-8.

Neuringer, C. (1961). Dichotomous evaluations in suicidal individuals. Journal of Consulting Psychology, 25, 445-449.

Oshio, A. (2009a). Development and validation of the dichotomous thinking inventory. Social Behavior and Personality: An International Journal, 37, 729-742.

Oshio, A. (2009b). Dichotomous thinking and the extreme views of others. Poster presented at the ISSID 2009 (International Society for the Study of Individual Differences). Evanston U.S.A..

Oshio, A. (2012). Relationship between dichotomous thinking and music preferences among Japanese undergraduates. Social Behavior and Personality: An International Journal, 40, 567-574.

Oshio, A. (in press). An all-or-nothing thinking turns into darkness: Relations between dichotomous thinking and personality disorders. Japanese Psychological Research.

Shih, S. (2011). Perfectionism, implicit theories of intelligence, and Taiwanese eighth-grade students' academic engagement. The Journal of Educational Research, 104, 131-142. 